\title{
Experimental study of fungal release characteristics in central air conditioning systems
}

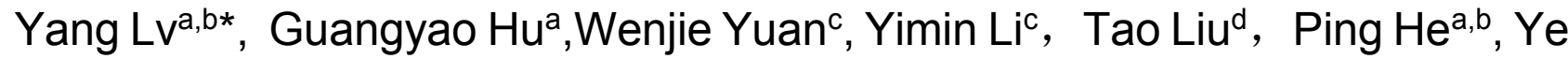 \\ Wang ${ }^{\mathrm{a}, \mathrm{b}}$, Yuhe Sheng ${ }^{\mathrm{a}, \mathrm{b}}$
}

aSchool of Civil Engineering, Dalian University of Technology, Dalian, China

bNational Demonstration Center for Experimental Civil and Hydraulic Engineering Education,

Dalian University of Technology, Dalian, China

'School of Life Science and Biotechnology, Dalian University of Technology, Dalian, China

dSchool of Environmental Science and Technology, Dalian University of Technology, Dalian, China

a,b Ivyang@dlut.edu.cn

Keywords: Microbe; Fungal spore; Genome sequencing; Release; Parallel air flow; Air conditioning system

Abstract. The biological pollution of air conditioning system is one of the most important problems in indoor pollution. Then measurement device of fungal spore release strength in the parallel airflow was developed, and the release intensity of two kind of fungal spores was tested in typical wind speed and environmental humidity. The results showed that the relative humidity and airflow characteristics were the main factors influencing the spore release strength. Based on the data of experiment, this paper fitted the release intensity with wind speed and environmental humidity.

\section{Introduction}

In recent years, SARS, H1N1, H7N9 and other virus spread ${ }^{1-2}$, more and more attention has been paid to the increasingly serious problem of indoor air pollution. Studies showed that air handing unit is an important source of microorganisms for indoor biological pollution. For air handling units, the humidity is relatively high. The fungus are common air pollutant in indoor environment and air conditioning system. At present, the aerosolization method of fungal spores is jet-flow, and the data obtained can be used to predict the maximum concentration of fungal spores in the $\operatorname{air}^{3-4}$.The fungal spores in the air conditioning system is inspired by the air flow, mostly by the parallel air flow on surface rather than by the jet-flow, such as through the inner surface of the pipe in the air conditioning system, the surface of the cooler and the surface of the air filter. Therefore, a fungal spore release strength tester was developed based on environmental humidity and parallel airflow the change. The aim of the present study was to clarify the pollution and release characteristics of the microorganisms in air conditioning systems.

\section{Development of fungal spore release strength tester}

The 6 level Andersen microbial sampler was used in this system and only the first level of the Andersen sampler was used during the test since this test only recorded the number of spores and did not distinguish the particle size of spores. According to Jones's research, using only one sample can ensure reliable results, but also greatly reduce the workload.

The design of parallel air flow and the control of flow rate is the key to the device. The system flow was fixed as the Anderson sampler flow is $28.3 \mathrm{~L} / \mathrm{min}$, In order to achieve the $0.6-7.2 \mathrm{~m} / \mathrm{s}$ wind speed which is common in air conditioning system and indoor air speed range, the device adopts variable cross-section structure. The wind speed was calculated as follows.

$$
\mathrm{v}=\frac{28.3 \times 10^{-8}}{60 \times A}
$$

$\mathrm{V}$ is the wind speed on colony surface, $\mathrm{m} / \mathrm{s}$; $\mathrm{A}$ is the area of the slit, $\mathrm{m}^{2}$. 
Figure 1 is the design of the 4 kinds of air flow channel, the experiment produced a total of 4 kinds of air duct, and 4 kinds of wind speed $(0.6 \mathrm{~m} / \mathrm{s}, 2.4 \mathrm{~m} / \mathrm{s}, 4.7, \mathrm{~m} / \mathrm{s}, 7.2 \mathrm{~m} / \mathrm{s})$ can be achieved. The parallel airflow with different wind speeds can be realized by changing the area of the cross section of the air flow channel. The air channel of the cross section structure is connected with a flange, which is convenient for remove and replacement. The test piece is arranged on the side wall of slit cross section, and the airflow can be parallel to the surface of the fungus after being installed on the test piece. The experiment conducted in a closed test chamber, and the humidity in test chamber was controlled by humidifier/dehumidifier, and the temperature was measured by temperature and humidity tester.

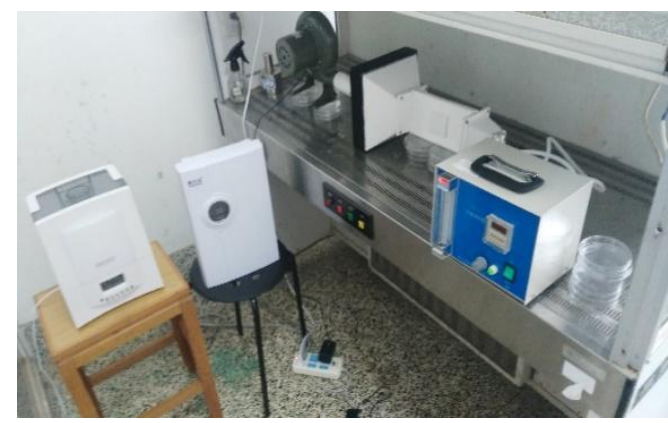

Figure 1. Test equipment and parallel flow slit device

Dominant fungi in air conditioning system were purchased in China Center of Industrial Culture Collection (CICC): Cladosporium spp. (2665), Penicillium spp. (40279). The stainless steel plate (commonly used in air duct material) and non-woven fabrics (commonly used in filter materials) were selected as the surface material for experiment. According to the study by Gorny $70 \%-80 \%$ fungal spore was released in the first 10 minutes, and the test time is about 10 minutes. Each group set up three groups of parallel test. Three relative humidity gradient $(50 \%, 65 \%, 80 \%)$ were setted. The experimental relative humidity error $\pm 2 \%$ after observation.

The experiment was conducted in the closed experimental chamber. Disinfection and open dehumidifier / humidifier to ensure the cleanliness and relative humidity test chamber. The system was adjusted before each test run. The rotor flowmeter was adjusted to ensure that the flow was fixed to $28.3 \mathrm{~L} / \mathrm{min}$, to keep the sample inlet normal. After opening the system and the super clean worktable $3 \mathrm{~min}$, ensured that the clean airflow was obtained. The test material with the fungal colony was placed in the slit to release the spores, and the experimental conditions were shown in Table 1.

Table 1. Test conditions

\begin{tabular}{ccccc}
\hline fungi & environment condition & $\begin{array}{c}\text { sample } \\
\text { time }\end{array}$ & $\begin{array}{c}\text { wind } \\
\text { speed }\end{array}$ & Experimental settings \\
\hline Cladosporium & & & $0.6 \mathrm{~m} / \mathrm{s}$ & It was repeated 3 times \\
$(2665)$ & $28-32^{\circ} \mathrm{C}$, & $10 \mathrm{~min}$ & $2.4 \mathrm{~m} / \mathrm{s}$ & $\begin{array}{c}\text { for each strain } \\
\text { Penicillium }\end{array}$ \\
(40279) & $\mathrm{RH}(50 \% / 65 \% / 80 \%)$ & & $7.2 \mathrm{~m} / \mathrm{s}$ & $/$ material $/$ wind speed \\
\hline
\end{tabular}

Samples of the fungi were cultured by PDA culture medium and were counted after cultured for 5 days in $28^{\circ} \mathrm{C}$. The device and sampler were regularly disinfected with $70 \%$ alcohol wipe disinfection every time. All the instruments are disinfected before used.

Figure 2 is the result of the experimental test, the number of fungal spores released $\mathrm{N}=$ total number of colonies / fungal surface area of the material. It can be seen in the results, in parallel flow, compared to Penicillium, Cladosporium more easily released fungal spores, and fungal spore release strength was relatively low in higher relative humidity release. With the increase of air velocity, the release quantity of fungal spores increased significantly. The results were consistent with the research of Gregory and Zoberi, it can be known that the tester can effectively measure the fungal spore release strength. 


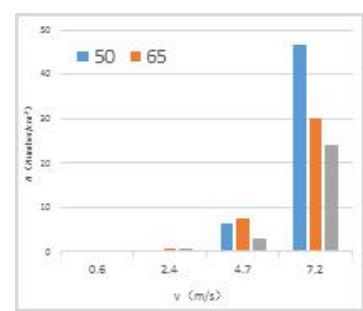

(1)

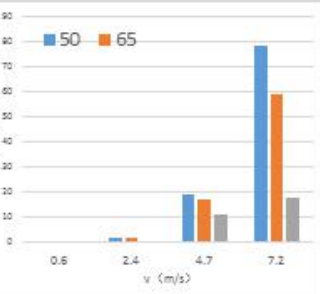

(2)

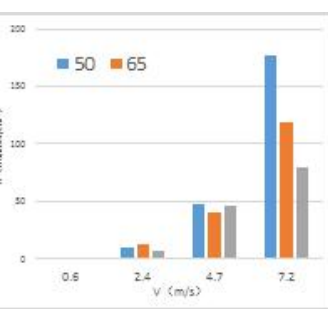

(3)

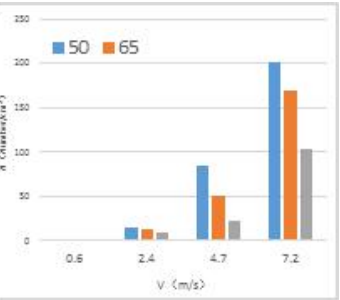

(4)

(1) non-woven fabrics(2665) (2) stainless steel plate(2665)

(3) non-woven fabrics(40279) (4) stainless steel plate(40279)

Figure 2 The test result of Cladosporium(2665)/Penicillium (40279)spore release strength

\section{Statistical model of fungal spore release intensity}

The spore released is relatively small in the low wind speed conditions. In order to ensure the accuracy, the spore released number under $7.2 \mathrm{~m} / \mathrm{s}$ was selected as fitting data, $\mathrm{f}(\mathrm{x})$ represents the number of spore release, and $\mathrm{X}$ represents the relative humidity. The fitting curves of the two materials are shown in Table 2 and 3.

$\underline{\text { Table 2. Curve fitting parameters of stainless steel plate material }}$

\begin{tabular}{|c|c|c|c|c|c|}
\hline \multirow{2}{*}{ Material } & \multirow{2}{*}{ Strain } & \multicolumn{4}{|c|}{$f(x)=a * \sin \left(b^{*} x+c\right)$} \\
\hline & & $\mathrm{a}$ & $b$ & $\mathrm{c}$ & $\mathrm{r}$ \\
\hline \multirow{2}{*}{ Stainless steel plate } & Cladosporium & 78.51 & 4.106 & 5.945 & 1 \\
\hline & Penicillium & 201.7 & 3.1 & 6.411 & 1 \\
\hline ur & narameters 0 & \multirow{2}{*}{\multicolumn{3}{|c|}{$f(x)=a^{*} x^{\wedge} b$}} & \\
\hline Material & Strain & & & & \\
\hline \multirow{2}{*}{ Non-woven fabrics } & Cladosporium & 16.55 & -1.478 & 0.989 & \\
\hline & Penicillium & 56.62 & -1.647 & 0.997 & \\
\hline
\end{tabular}

It can be seen that, the relationship between spore number and relative humidity between the release can be respectively $\mathrm{f}(\mathrm{x})=\mathrm{a}^{*} \sin \left(\mathrm{b}^{*} \mathrm{x}+\mathrm{c}\right), \mathrm{f}(\mathrm{x})=\mathrm{a}^{*} \mathrm{x}^{\wedge} \mathrm{b}$ of the stainless steel plate and non-woven materials separately, coefficient of corresponding changes with different strains, and it has a high correlation coefficient. Under the experimental conditions, the greater the relative humidity, the more difficult to release fungal spores.

Because the Cladosporium almost no spore release in $0.6 \mathrm{~m} / \mathrm{s}, 2.4 \mathrm{~m} / \mathrm{s}$, and error can be large with less data fitting. So only the relation between Penicillium spore release strength and speed was fitted. F (x) represents the number of spore release, $\mathrm{X}$ represents wind speed.

Table 4. The fit of fungal spore release intensity and wind speed

\begin{tabular}{|c|c|c|c|c|c|}
\hline \multirow{2}{*}{ Material } & \multirow{2}{*}{ strain } & \multicolumn{3}{|c|}{$f(x)=a^{*} x^{\wedge} b$} & \multirow{2}{*}{$\begin{array}{l}\text { Relative } \\
\text { humidity }\end{array}$} \\
\hline & & $\mathrm{a}$ & $\mathrm{b}$ & $\mathrm{r}$ & \\
\hline \multirow{4}{*}{ Non-woven fabrics } & \multirow{6}{*}{ Penicillium } & 0.4382 & 3.038 & 0.9992 & $50 \%$ \\
\hline & & 1.048 & 2.391 & 0.9967 & $65 \%$ \\
\hline & & 3.27 & 1.627 & 0.9826 & $80 \%$ \\
\hline & & 3.06 & 2.121 & 0.9982 & $50 \%$ \\
\hline \multirow[t]{2}{*}{ Stainless steel plate } & & 0.7198 & 2.766 & 0.9983 & $65 \%$ \\
\hline & & 0.1272 & 3.389 & 0.9937 & $80 \%$ \\
\hline
\end{tabular}

It can be seen that the relationship between the number of spores released and the wind speed can be fitted by $\mathrm{F}(\mathrm{x})=\mathrm{a} * \mathrm{x}^{\wedge} \mathrm{b}$, and has a high correlation coefficient.

Penicillium data was selected, and fit the data based on relative humidity and wind speed by MATLAB software. $f(x)$ represents the number of spore release, $X$ and $Y$ represents wind speed, 
relative humidity separately, the fit is shown in Table 5 shown in Figure 3, under the experimental conditions, the prediction accuracy is higher using this model.

Table 5 The fit of fungal spore release intensity with wind speed and relative humidity

\begin{tabular}{|c|c|c|c|c|c|c|c|c|}
\hline \multirow{2}{*}{ Material } & \multicolumn{7}{|c|}{$f(x, y)=a+b^{*} \sin \left(c^{*} y+d\right)+e^{*} x^{\wedge} f+g$} & \multirow[b]{2}{*}{$\mathrm{r}$} \\
\hline & $\mathrm{a}$ & b & $\mathrm{c}$ & $\mathrm{d}$ & $\mathrm{e}$ & $\mathrm{f}$ & $\mathrm{g}$ & \\
\hline $\begin{array}{l}\text { Stainless } \\
\text { steel plate }\end{array}$ & $\begin{array}{c}11.79 \\
0\end{array}$ & -7.831 & 8.027 & -4.881 & 1.065 & 2.397 & -7.310 & 0.8849 \\
\hline $\begin{array}{c}\text { Non-wove } \\
\mathrm{n} \text { fabrics }\end{array}$ & -0.992 & 4.709 & 4.771 & 0.0749 & 1.556 & 2.329 & 2.711 & 0.8826 \\
\hline
\end{tabular}

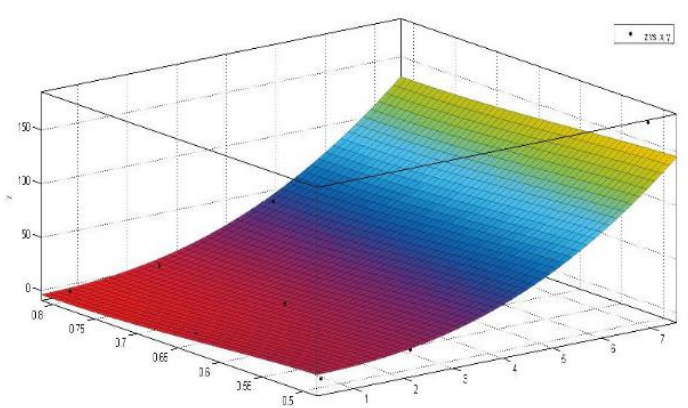

A non-woven fabrics

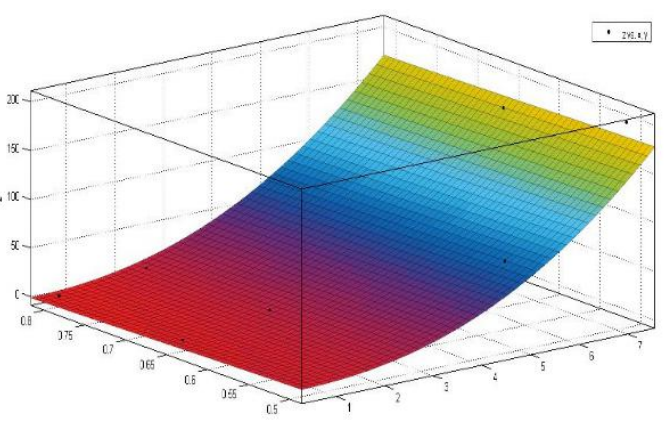

B stainless steel plate

Figure 3. The test result of Penicillium spore release strength

\section{Conclusions}

The fungal spore release strength is associated with air velocity and relative humidity, air velocity maybe greater than a certain value to make the spore release. The statistical release intensity model of Penicillium spores can be expressed as the form of power function $\mathrm{y}=\mathrm{AX} \wedge \mathrm{B}$ under the wind speed range of $0.6-7.2 \mathrm{~m} / \mathrm{s}$. When the wind speed and relative humidity were chosen as independent variable, the statistical model can be expressed as $\mathrm{f}(\mathrm{x}, \mathrm{y})=\mathrm{a}\left(\mathrm{c}^{*} \mathrm{y}+\mathrm{d}\right)+\mathrm{b}^{*} \sin +\mathrm{e}^{*} \mathrm{x}^{\wedge} \mathrm{f}+\mathrm{g}$, and the statistical model has high accuracy.

\section{Acknowledgements}

This work was financially supported by the National Nature Science Foundation of China (51308088), the China Environmental Protection Project (201509063), the National Nature Science Foundation of China $(91743102,51578103)$ and Innovation and entrepreneurship training program for college students in Dalian University of Technology(615).

\section{References}

[1] Lee, Nelson. et al. A major outbreak of severe acute respiratory syndrome in Hong Kong. New England Journal of Medicine. 348(20), 1986-1994 (2003).

[2] Li, Tiegang. et al. Epidemiological investigation of an outbreak of pandemic influenza A (H1N1) 2009 in a boarding school: serological analysis of 1570 cases. Journal of Clinical Virology. 50(3), 235-239 (2011).

[3] Cho, S.H., Seo, S.C., Schmechel, D., Grinshpun, S.A., Reponen, T. Aerodynamic characteristics and respiratory deposition of fungal fragments. Atmospheric Environment 39 (30), 5454-5465(2005).

[4] GORNY R L, REPONEN T, GRINSHPUN S A. et a1. Source strengh of fungal spore aerosulization from moldy building material. atmosphere. Environ, 35,4853-4862(2001). 